\title{
Leg ulcers in sickle cell patients: management challenges
}

\author{
Arij M El Khatib' \\ Shady $\mathrm{N} \mathrm{Hayek}^{2}$ \\ 'Division of Plastic and \\ Reconstructive Surgery, Department \\ of Surgery, American University of \\ Beirut Medical Center (AUBMC), \\ ${ }^{2}$ Private Practice, Cosmetic Surgery \\ Center, Beirut, Lebanon
}

This article was published in the following Dove Press journal:

Chronic Wound Care Management and Research

I5 November 2016

Number of times this article has been viewed

\begin{abstract}
Sickle cell disease is an autosomal recessive hemoglobinopathy caused by an amino acid substitution from glutamic acid to valine in the beta hemoglobin chain. One of the common symptoms occurring in sickle cell patients are leg ulcers, which are notoriously painful, difficult to treat, and frequently recurrent. These ulcers pose a therapeutic challenge with multiple modalities proposed for treatment, but with scarce evidence of efficacy of any single modality. Ulcer prevention, rigorous wound care, pain control, and surgery are the current mainstays of sickle cell leg ulcer treatment.
\end{abstract}

Keywords: sickle cell leg ulcer, leg wound, sickle cell disease

\section{Introduction}

Sickle cell disease (SCD) is an autosomal recessive hemoglobinopathy caused by an amino acid substitution from glutamic acid to valine in the beta hemoglobin chain. ${ }^{1,2}$ This results in defective hemoglobin molecules designated hemoglobin $\mathrm{S}$ that causes sickling or clumping of red blood cells, resulting in vaso-occlusion, ischemia, inflammation and organ damage, as well as hemolytic anemia. ${ }^{2}$ SCD affects multiple organ systems and manifests diverse symptoms, such as pain crises, pulmonary hypertension, avascular necrosis of hip/shoulder joints, priapism, and leg ulcers.

Leg ulcers in patients with SCD are a common symptom and can vary in incidence among different phenotypes of the condition and geographical area, ${ }^{1}$ occurring in up to $75 \%$ of adults affected with the disease in some populations. ${ }^{2-4}$ Incidence of leg ulcers is highest among male adult patients from low socioeconomic backgrounds. ${ }^{2,5,6}$ Ulcers in patients with SCD are considered a marker of disease severity, with problematic ulcers commonly occurring in association with pulmonary hypertension and priapism. ${ }^{7}$ Ulcers normally occur in the lower extremities, in areas of thin skin, scarce subcutaneous fat, and low blood flow. ${ }^{2,7}$ Prominent locations are the malleoli, with the medial malleolus being more frequently affected than the lateral. ${ }^{2,4,7,8}$

Hallmark features of sickle cell leg ulcers are their indolent clinical courses and high recurrence rates despite appropriate therapy, ${ }^{2,9}$ with some studies quoting the recurrence at $80 \%-97 \% 2$ years after wound closure, ${ }^{2,3}$ thereby making this a prominent problem and a cause of morbidity, decreased functionality, and low quality of life. ${ }^{10}$ These features makes chronic wound care an important adjunct in sickle cell patient care. While there are multiple therapies being used today for care of leg ulcers, most therapeutic modalities have minimal evidence supporting their efficacy.
Correspondence: Arij M El Khatib Division of Plastic and Reconstructive Surgery, Department of Surgery, American University of Beirut Medica Center (AUBMC), P.O. Box II-0236, Beirut II 07 2020, Lebanon

Tel $+96 \mid$ | 3989 |2|

Fax+961 | 36329 |

Email ae45@aub.edu.lb 


\section{Pathophysiology}

Leg ulcers in patients with SCD are often described as punched out wounds with raised edges, necrotic debris within the wound, and sloughing surrounding the ulcerated area. ${ }^{2}$ They commonly have a yellowish biofilm and a significant amount of exudate. While systemic infection due to a sickle leg ulcer is rare, it should be considered in cases of otherwise unexplained septicemia. Another concern in patients with these ulcers is erosion of soft tissues to the level of the bone and subsequent osteomyelitis. Appropriate imaging, biopsies, and cultures must be taken in all cases raising a suspicion of underlying osteomyelitic changes. ${ }^{7}$

The exact pathophysiology of leg ulcers in SCD patients is unknown, and the causative mechanism is thought to be multifactorial. ${ }^{2,7}$ Etiologic factors include the sickling of red blood cells in blood vessels, causing vaso-occlusion and impairing oxygen delivery to tissues; as well as the binding of hemolysis-freed hemoglobin to nitric oxide, deactivating it and subsequently resulting in vasoconstriction. ${ }^{1,8,11}$ Blood viscosity and inflammatory factors are also being studied to determine whether these are increased in patients manifesting chronic leg ulcers and whether they have an impact on the development of ulcer. Recent evidence also indicates that there is an element of venous incompetence in sickle cell patients. ${ }^{1,2,8}$ All the earlier mechanisms can either occur spontaneously in a patient with SCD, or alternatively be caused by trauma, which may start a cascade of the aforementioned mechanisms, leading to ulcer formation. ${ }^{1,3}$

\section{Challenges}

The two major challenges in leg ulcer management in patients with SCD are the prolonged course to recovery and the high recurrence rate of healed or grafted ulcers. Both these challenges are due to the fact that the therapies used, whether local wound care or surgical interventions, do not modify the pathophysiologic factors that have led to the occurrence of the leg ulcers, and the same factors are therefore at play causing the healed or grafted skin to ulcerate.

Due to the long and difficult course of treatment of ulcers in SCD patients, as well as the impairment of function and detrimental effects of these ulcers on quality of life, it is beyond doubt that prevention is of utmost importance. The most important factor in ulcer prevention is patient education on the stringent care and preventive measures that need to be taken to prevent leg trauma that may be a causative factor in the complex chain of events leading to a chronic nonhealing ulcer. Careful trauma prevention, early treatment of minor trauma/wounds, use of insect repellents to prevent bites, use of compression stockings, and leg elevation to prevent venous incompetence are all mainstays of prevention of leg ulcer occurrence in patients with SCD and every patient with SCD should receive ample education on these measures. ${ }^{2,7}$

Another significant challenge to proper care of leg ulcer in patients with SCD is the significant pain associated with these lesions. ${ }^{1,4}$ The constant pain associated with these lesions, as well as the intolerability of dressing changes, makes wound care difficult and decreases patient compliance with wound care regimens. Analgesia is therefore a cornerstone of leg ulcer care and should be given special consideration by treating physicians. The analgesic agents used for pain control include systematic treatment agents, such as nonsteroidal anti-inflammatory agents, for weak and moderate pain and narcotics for more severe pain episodes. ${ }^{1,4}$ Additionally, local anesthetics and anesthetic-imbibed dressings have been used as topical pain control. For painful neuropathic ulcers, the same agents that are used for treating diabetic ulcers are prescribed, such as selective serotonin uptake inhibitors and gabapentin. ${ }^{1,4}$ Ulcer analgesia in patients with SCD is challenging, as classes of different medications have to be managed to keep a balance and allow the patient pain relief and ability to perform activities of daily living, and at the same time minimize drowsiness and other medication side effects as well as patient apprehension about prescription medication dependence.

\section{Management options}

Therapies currently used for the management of leg ulcers in patients with SCD revolve around overall disease control, wound care and dressings, debridement, and surgical management with skin grafts or flaps.

There are no disease-specific medications for control or treatment of SCD and the most commonly used therapies are hydroxyurea and blood transfusions. Hydroxyurea is the only Food and Drug Administration-approved drug for sickle cell treatment, ${ }^{1,11}$ and while its mechanism of action has not been fully elucidated, it has been shown to increase fetal hemoglobin levels, therefore decreasing red blood cell sickling. Although hydroxyurea has been shown to have favorable effects on many symptoms of SCD, its effects on leg ulcers are not as clear-cut. While high fetal hemoglobin levels are arguably associated with decreased severity of leg ulcers, there have been multiple reports of leg ulcers arising due to hydroxyurea use, which showed improvement upon discontinuation of the drug., ${ }^{3,5,12}$ One study has shown that hydroxyurea impairs the migration of angiogenic bodies; this may be the causative mechanism of leg ulcer 
occurrence and subsequent improvement upon hydroxyurea discontinuation. ${ }^{11}$

Blood transfusions have also been traditionally used to alleviate sickle cell symptoms, including chronic nonhealing leg wounds, based on the premise that higher hemoglobin levels and subsequent better oxygenation should lead to better healing. Although blood transfusions have been shown to be effective in acute chest syndrome and pulmonary hypertension, ${ }^{7}$ evidence of efficacy of this therapeutic modality on leg ulcers has been scarce due to the absence of prospective randomized trials. ${ }^{1,2,7}$

Zinc is believed to have a role in wound healing. Zinc levels have been found to be low in patients with SCD and oral supplementation with $220 \mathrm{mg}$ of zinc three times daily has been found to hasten leg ulcer healing. The article citing this was written in 1975 with one in seven ulcers healing and two showing improvement. . $^{3,5,7,13}$

Local wound care is imperative for treatment of ulcers in patients with SCD. Patients are encouraged to keep ulcers clean, with proper cleansing of the wounds using soap and water, or normal saline solution. Numerous types of topical therapies have been described and utilized for local wound care of leg ulcers in patients with SCD, including moisturizing, antibacterial, inflammation-modulating, matrixmodulating dressings, ${ }^{14-16}$ as well as laser treatments and negative pressure therapy. ${ }^{17,18}$ While all these modalities have shown anecdotal efficacy, clear evidence as to the superiority of one over the others is lacking. Many physicians also use compression therapy; and although evidence is scarce, it may be of use in modifying the role venous congestion plays in leg ulcer pathophysiology. ${ }^{1,2,8}$

The use of a triple antibiotic cream has been advocated for the treatment of ulcers in patients with SCD after a prospective trial showed a statistically significant decrease in ulcer size. ${ }^{19}$ The study population, however, had only 15 patients. ${ }^{19}$

A review by Cochrane in 2014 cited a clinical trial using an arginine-glycine-aspartic acid peptide matrix on sickle cell leg ulcers as the only trial achieving noticeable benefit after treatment, with statistically significant decrease in sickle cell leg ulcer size. The Cochrane Group, however, also stated that the study carries a risk of bias and recommends further studies. ${ }^{20}$

Heparan sulfate, a synthetic heparin sulfate solution, is believed to have wound-modifying effects, such as modulation of vascular endothelial growth factor and transforming growth factor $\beta 1$ among others, thereby promoting angiogenesis, decreasing inflammation, and improving wound healing. It has been used in wounds caused by chronic arterial insufficiency, burns, radiotherapy, and pressure with some evidence of decrease in pain and wound size. In one case report, it was shown to have similar effects on a leg ulcer in a patient with SCD. ${ }^{21}$ The authors have had favorable experiences when applying heparin sulfate to wound beds twice a week (Figures 1 and 2).

Autologous platelet gel has been tried in the treatment of sickle cell ulcers in five patients, showing some reduction in ulcer size. ${ }^{19}$ The results are also hypothesized to be due to modifying effects on inflammatory mediators in the wound bed. ${ }^{19}$

Negative pressure wound therapy has been reported to be beneficial in healing chronic wounds of multiple etiologies. Opara et al have reported its effectiveness in bringing 15 ulcers in nine patients with SCD to a graftable state within 6-10 days of negative pressure wound therapy use, and subsequent skin graft take of $98 \%-100 \%$ in all ulcers. Paggiaro et al reported better graft survival in one wound that had pressure wound therapy compared to two other wounds treated with calcium alginate or rayon and saline dressing, respectively. ${ }^{17,22}$

One report of low-level laser therapy use in a chronic sickle ulcer has shown significant reduction in ulcer size. It

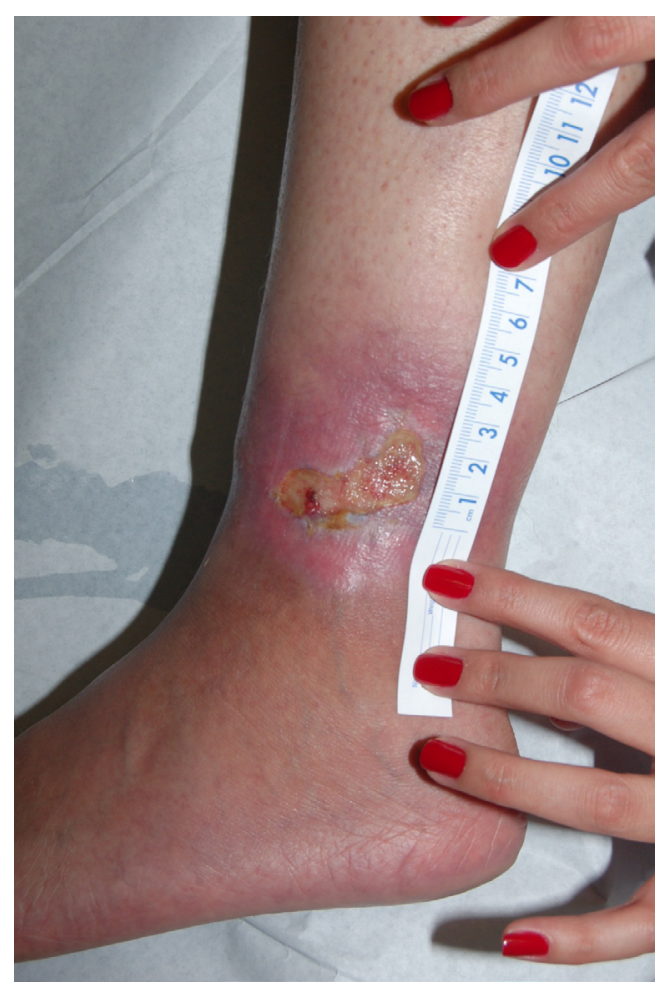

Figure I Leg ulcer in a 23-year-old patient with sickle cell disease, not responsive to topical antibiotic dressings for 2 months. 


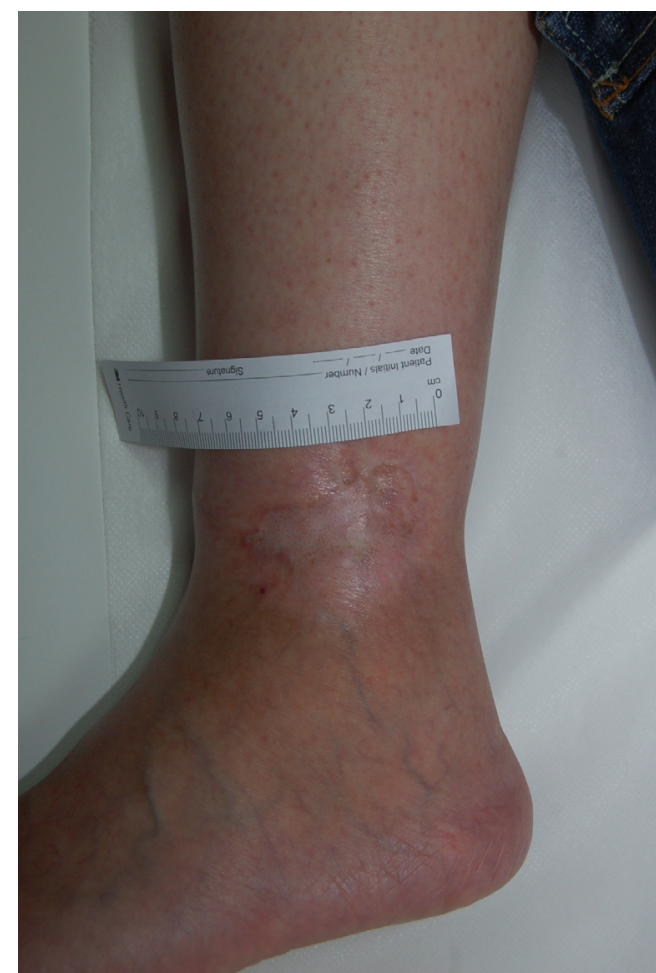

Figure 2 Healed ulcer in 23-year-old patient after 4 weeks of twice-weekly heparan sulfate dressings.

is believed that low-level lasers may have an effect on the inflammatory processes and wound matrix. ${ }^{18}$

A variety of trials have used different types of skin substitutes and allogenic keratinocytes have shown some improvement in a small number of sickle cell leg ulcers, but the scarce evidence and overwhelming cost of these treatment modalities limit their use. ${ }^{19}$

The nature of ulcers, with significant amounts of necrotic tissue and adherent biofilm, necessitates frequent debridement in patients with SCD. This may be chemical, using the previously mentioned dressing types, or mechanical. Mechanical debridement can be performed during dressing changes by scraping off the topmost layer of the ulcer using gauzes or surgical instruments, but it is most effective when done under controlled conditions in the operating room with the patient receiving adequate analgesia and anesthesia. Debridement serves to cleanse the wound of its necrotic, senescent cells, inflammatory, and bacterial loads. ${ }^{2-4}$

The surgical reconstructive options used for leg ulcers in patients with SCD are most commonly skin grafts, and less frequently regional/distant flaps. The advantages of skin grafts revolve around the ease of surgery, but skin grafts on leg ulcers often fail acutely or after healing, most probably due to the poor vascularity of the underlying ulcer bed, leading to ulcer recurrence. The advantage of regional/distant flaps pertains to the fact that they derive their blood supply from outside the wound bed.
These, however, are more complex, costly, and time-consuming surgeries and also carry significant failure rates.

\section{Conclusion}

Leg ulcers are a significant cause of morbidity in SCD patients, and despite the presence of multiple management modalities, strong evidence on optimal care is scarce and these wounds are characterized by an indolent course and high recurrence rates. Prevention and early intervention should therefore be the mainstays of treatment. New data are needed on the efficacy and outcomes of the multiple available treatments. Therefore, registers of patients with sickle cell ulcers and their medical courses are imperative in advancing knowledge and improving the complex care of these patients.

\section{Disclosure}

The authors report no conflicts of interest in this work.

\section{References}

1. Ladizinski B, Bazakas A, Mistry N, Alavi A, Sibbald RG, Salcido R. Sickle cell disease and leg ulcers. Adv Skin Wound Care. 2012;25(9): 420-428.

2. Trent JT, Kirsner RS. Leg ulcers in sickle cell disease. Adv Skin Wound Care. 2004;17(8):410-416.

3. Vasconcelos A, Prior AR, Ferrão A, Morais A. An adolescent with sickle cell anaemia experiencing disease-related complications: priapism and leg ulcer - a management challenge. BMJ Case Rep. 2012;2012:bcr1120115146. Available from: http://www.ncbi.nlm.nih. gov/pubmed/22605005. Accessed April 2, 2016.

4. SaunthararajahY, Vichinsky EP. Sickle cell disease: clinical features and management. In: Hoffman R, Silberstein LE, Weitz J, editors. Hematology: Basic Principles and Practice. Philadelphia: Elsevier Saunders; 2013:548-572.

5. Delaney KM, Axelrod KC, Buscetta A, et al. Leg ulcers in sickle cell disease: current patterns and practices. Hemoglobin. 2013;37(4):325-332. Available from: http://www.ncbi.nlm.nih.gov/pubmed/?term=)+Dela ney $+\mathrm{KM}+\% 2 \mathrm{C}+$ Axelrod $+\mathrm{KC} \% 2 \mathrm{C}+\mathrm{Buscetta}+\mathrm{A} \% 2 \mathrm{C}+\mathrm{et}+\mathrm{al} .+\mathrm{Leg}+\mathrm{u}$ lcers + in + sickle + cell + disease $\% 3 \mathrm{~A}+$ current + patterns + and + practices. Accessed April 2, 2016.

6. Connes P, Lamarre Y, Hardy-Dessources MD, et al. Decreased hematocrit-to-viscosity ratio and increased lactate dehydrogenase level in patients with sickle cell anemia and recurrent leg ulcers. PLoS One. 2013;8(11):e79680. Available from: http://www.ncbi.nlm.nih.gov/pub $\mathrm{med} /$ ?term $=$ Connes $+\mathrm{P} \% 2 \mathrm{C}+$ Lamarre $+\mathrm{Y} \% 2 \mathrm{C}+$ Hardy-Dessources $+\mathrm{M}$ $\mathrm{D} \% 2 \mathrm{C}+\mathrm{et}+\mathrm{al}$.+Decreased+hematocrit-to-viscosity+ratio+and+increa sed+lactate+dehydrogenase+level + in + patients + with + sickle + cell + ane mia+and+recurrent+leg+ulcers. Accessed April 2, 2016.

7. Minniti CP, Eckman J, Sebastiani P, Steinberg MH, Ballas SK. Leg ulcers in sickle cell disease. Am J Hematol. 2010;85(10): 831-833.

8. Bowers AS, Reid HL, Greenidge A, Landis C, Reid M. Blood viscosity and the expression of inflammatory and adhesion markers in homozygous sickle cell disease subjects with chronic leg ulcers. PLoS One. 2013;8(7):e68929. Available from: http://www.ncbi.nlm.nih.gov/pubm ed/?term $=$ Bowers + AS $\% 2 \mathrm{C}+$ Reid $+\mathrm{HL} \% 2 \mathrm{C}+$ Greenidge $+\mathrm{A} \% 2 \mathrm{C}+\mathrm{Landi}$ $\mathrm{s}+\mathrm{C} \% 2 \mathrm{C}+$ Reid + M. + Blood + viscosity + and + the + expression + of + inflam matory+and + adhesion + markers + in + homozygous + sickle + cell + disease +subjects+with+chronic+leg+ulcers. Accessed April 2, 2016.

9. Da Silva RR, Pereira MC, Melo Rêgo MJ, et al. Evaluation of Th17 related cytokines associated with clinical and laboratorial parameters in sickle cell anemia patients with leg ulcers. Cytokine. 2014;65(2): 143-147. 
10. Dampier C, LeBeau $P$, Rhee $S$, et al. Health-related quality of life in adults with sickle cell disease (SCD): a report from the comprehensive sickle cell centers clinical trial consortium. Am J Hematol. 2011;86(2): 203-205.

11. Lopes FC, Ferreira R, Albuquerque DM, et al. In vitro and in vivo antiangiogenic effects of hydroxyurea. Microvasc Res. 2014;94:106-113.

12. Nzouakou R, Bachir D, Lavaud A, et al. Clinical follow-up of hydroxyurea-treated adults with sickle cell disease. Acta Haematol. 2011;125(3): $145-152$.

13. Prasad AS, Schoomaker EB, Ortega J, Brewer GJ, Oberleas D, Oelshlegel FJ Jr. Zinc deficiency in sickle cell disease. Clin Chem. 1975;21(4): 582-587.

14. Reindorf CA, Walker-Jones D, Adekile AD, Lawal O, Oluwole SF. Rapid healing of sickle cell leg ulcers treated with collagen dressing. J Natl Med Assoc. 1989;81(8):866-868.

15. Minniti CP, Gorbach AM, Xu D, et al. Topical sodium nitrite for chronic leg ulcers in patients with sickle cell anaemia: a phase 1 dose-finding safety and tolerability trial. Lancet Haematol. 2014;1(3):e95-e103.

16. Romanelli M, Dini V, Romanelli P. Hydroxyurea-induced leg ulcers treated with a protease-modulating matrix. Arch Dermatol. 2007;143(10): 1310-1313.

17. Opara K, Okoro S, Jiburum B. Experience with the use of vacuumassisted closure therapy in the management of sickle cell leg ulcers. Eur J Plast Surg. 2012;35(3):213-220.
18. Bonini-Domingos CR, Valente FM. Low-level laser therapy of leg ulcer in sickle cell anemia. Rev Bras Hematol Hemoter. 2012;34(1) 64-67.

19. Altman IA, Kleinfelder RE, Quigley JG, Ennis WJ, Minniti CP. A treatment algorithm to identify therapeutic approaches for leg ulcers in patients with sickle cell disease. Int Wound J. Epub 2015 Nov 4. Available from: http://www.ncbi.nlm.nih.gov/pubmed/?term=Altman $+\mathrm{IA}+\% 2 \mathrm{C}+$ Kleinfelder+RE $\% 2 \mathrm{C}+$ Quigley $+\mathrm{JG} \% 2 \mathrm{C}+$ Ennis $+\mathrm{WJ} \% 2 \mathrm{C}+$ Minniti+CP.+A+treatment+algorithm+to+identify+therapeutic+approa ches+for+leg+ulcers+in+patients+with+sickle+cell+disease. Accessed April 2, 2016.

20. Martí-Carvajal AJ, Knight-Madden JM, Martinez-Zapata MJ. Interventions for treating leg ulcers in people with sickle cell disease. Cochrane Database Syst Rev. 2014;8(12):CD008394. Available from: http://www. ncbi.nlm.nih.gov/pubmed/25485858. Accessed April 2, 2016.

21. Hayek S, Dibo S, Baroud J, Ibrahim A, Barritault D. Refractory sickle cell leg ulcer: is heparan sulphate a new hope? Int Wound $J$. 2014;13(1):35-38. Available from: http://www.ncbi.nlm.nih.gov/pub $\mathrm{med} /$ ?term $=$ Hayek $+\mathrm{S} \% 2 \mathrm{C}+\mathrm{Dibo}+\mathrm{S} \% 2 \mathrm{C}+$ Baroud $+\mathrm{J} \% 2 \mathrm{C}+\mathrm{Ibrahim}+\mathrm{A}$ $\% 2 \mathrm{C}+$ Barritault + D. + Refractory + sickle + cell + leg + ulcer $\% 3 \mathrm{~A}+$ is + hepa ran + sulphate $+a+$ new + hope $\% 3 F$. Accessed April 2, 2016.

22. Paggiaro AO, Fernandes de Carvalho V, Fonseca GH, Doi A, Ferreira MC Negative pressure therapy for complex wounds in patients with sickle-cell disease: a case study. Ostomy Wound Manage. 2010;56(8):62-67.
Chronic Wound Care Management and Research

\section{Publish your work in this journal}

Chronic Wound Care Management and Research is an international, peer reviewed, open access, online journal publishing original research, reviews, editorials, and commentaries on the causes and management of chronic wounds and the major issues related to chronic wound management. Topics also include chronic wounds as comorbidities to other

\section{Dovepress}

conditions, patient adherence to therapy, and the economic burden of chronic wounds. The manuscript management system is completely online and includes a very quick and fair peer review system, which is all easy to use. Visit http://www.dovepress.com/testimonials.php to read real quotes from published authors. 